\title{
Book review: Paleoamerican Odyssey
}

\author{
Ariel David Frank
}

División Científica de Arqueología. Facultad de Ciencias Naturales y Museo, Universidad Nacional de La Plata / CONICET, Edificio Anexo Museo, 60 y 122 s/n (1900), La Plata, Buenos Aires, Argentina.

Email: frank.ariel@gmail.com

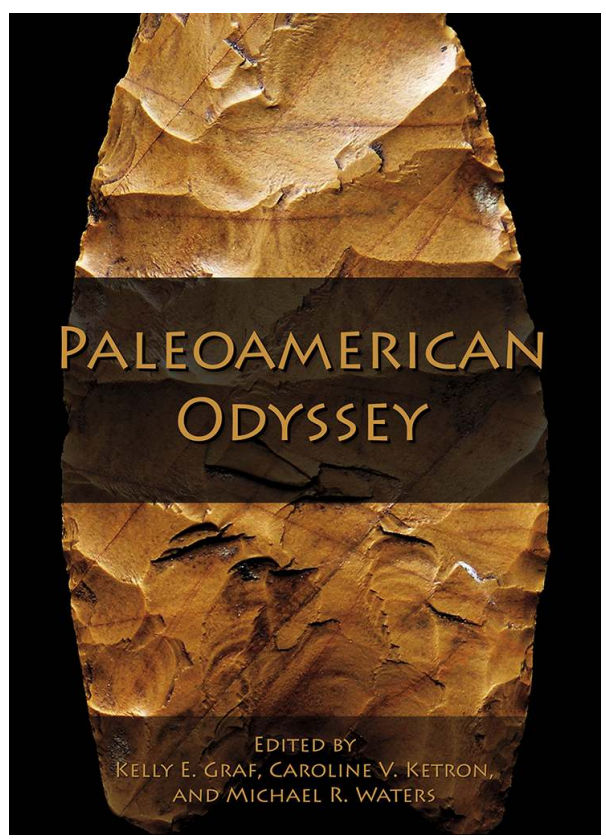

\section{Paleoamerican Odyssey}

edited by Kelly E. Graf, Caroline V. Ketron and Michael R. Waters

Texas A\&M University Press, 2014, pp. 584. ISBN 978-1-62349-192-5

http://www.tamupress.com/product/Paleoamerican-Odyssey,7924.aspx

Paleoamerican Odyssey collects 31 papers originally presented at the 2013 Conference by the same name. The book, which provides an up-to-date view of current discussions concerning the initial American peopling, compiles models, reviews of evidence and detailed analyses of sites and archaeological remains. It is organized in five sections. Here, only some chapters will be addressed.

Part One tries to contextualize the initial dispersion of people into the continent. It gathers six papers not only about Beringia, but also from Australia and Japan which are relevant for this topic. The discussion focuses on whether the first migration to America took

Published by the School of History, Classics and Archaeology, University of Edinburgh ISSN: 2055-0472. URL: http://journals.ed.ac.uk/lithicstudies/

This work is licensed under a Creative Commons Attribution 2.5 UK: Scotland License. 
place before or after the LGM. Pitulko et al. make a detailed description of the lithic reduction sequences recognized at Yana RHS site in Western Arctic Beringia, hinting at a possible preLGM human dispersal to the Americas. According to Graf, it is likely that Late Upper Paleolithic groups moved into the new world. Her position fits with the information presented by Potter et al. and Smith et al. from sites in Eastern Beringia.

Part Two is dedicated to debates about dispersal routes. Coastal and interior migration paths within North America are discussed. Information stemming from Archaeology, Paleoecology and Genetics is analyzed in five articles. Papers by Ives et al. and Erlandson address the Ice-free Corridor model. The former interprets the corridor between the Laurentide and Cordilleran ice sheets as a dynamic avenue of communication between distant zones, based mainly on the analysis of morphological and technological traits of fluted points as well as their distribution. Erlandson criticizes the traditional model and advocates for a Costal migration theory following the Pacific Rim.

Part three is a selection of seven studies regarding the long debated "Clovis Culture". Miller et al. review typological, geographical and chronological issues regarding this so called culture. Kilby and Huckell examine the characteristics of the caches and make thoughtprovoking inferences about mobility, knowledge of the landscape and functionality of this type of site. Beck and Jones compare Clovis with the Western Stemmed Tradition technocomplex in terms of technology, chronology and land-use pattern and propose the latter belonged to pre-Clovis groups. Bradley and Collins interpret Clovis as a cult rather than a culture, making an interesting link between archaeological evidence and the concept of cultural revitalization.

Part four is dedicated to Latin American archaeology. There are only five chapters in this section, which seems a little unbalanced for a book focused on the peopling of the Americas. Diverse topics are addressed. For instance, Dias and Bueno review archaeological evidence from the Pleistocene/Holocene transition from Brazil and discuss possible migration routes within South America. Flegenheimer et al. propose that colonizing peoples from the Pampas and Patagonia had a similar perception of the world, based mainly on the finding of great amounts of fishtail projectile points on hilltops. Dillehay focuses on the domestic architecture, niche construction and its implications for the study of the peopling of the New World.

The last part is called "Pre-Clovis Archaeology" and presents eight papers with evidence, experiments, arguments and models, aimed at discussing early sites and artifacts which in many cases have been previously disputed. Andrefsky performs experiments for the purpose of distinguishing human-made artifacts from naturally-broken lithics. This approach is useful when considering the lithics from ancient sites in Piauí, Brazil; Boëda et al. make a detailed analysis of the dates, stratigraphy and quartz remains from these sites. Collins et al. group pre-Clovis sites in seven cultural patterns and use this to propose maritime adaptations and entrances to America from Asia and Europe. Finally, papers by Adovasio and Pedler and Waters and Stafford are critical of the Clovis-first model and review how it became a dogma.

As these final chapters show, Clovis is a burden for many archaeologists, and even for this book, which dedicates a significant space to it. The challenge is, then, to address the peopling of America without having it at the centre of the debate. In spite of this, the book is an excellent compilation about the "Paleoamerican Odyssey", dealing with antiquity, dispersal routes, technology and subsistence. It should not be seen as a specialized volume on lithic analysis. In fact, very few articles address solely and specifically lithic studies. Instead, it should be considered a valuable example of the articulation between the study of lithics and other research avenues. 